\title{
A (in)eficácia de normas trabalhistas e discriminação interseccional da mulher no mercado de trabalho*
}

\author{
The (in) effectiveness of labor standards and intersectional \\ discrimination of women in the labor market
}

\author{
Bianca Lemos Coelho \\ Universidade Federal de Ouro Preto \\ Kyara Mariana Corgosinho Silva \\ Universidade Federal de Ouro Preto \\ RAINER BOMFIM \\ PUC-MG
}

RESUMO A reorganização simultânea do trabalho no campo assalariado e no campo doméstico na contemporaneidade impacta diretamente na discriminação do trabalho produtivo feminino, o qual atua de forma interseccional. A partir desse contexto jurídico-social, a presente pesquisa teórica volta-se para a análise do atual regime jurídico pátrio de proteção do trabalho feminino, mediante uma ótica interseccional, para averiguar as razões da ineficácia de tais normas no cotidiano brasileiro e sua relação com a divisão sexual do trabalho. Perpassando por um contexto de uma cultura com origens patriarcais e machistas que ainda permeiam a sociedade e, consequentemente, as leis. Nessa pesquisa jurídico-sociológica, foram adotados marcos teóricos do Direito do Trabalho em sua matriz da teoria geral jurídica, bem como em sua perspectiva da sociologia jurídica laboral, em uma concepção tridimensional da Ciência do Direito. Buscando uma articulação entre a disciplina jurídica e outros ramos conexos, como a sociologia e a filosofia.

Palavras-chave: Direito do trabalho; Trabalho da mulher; Divisão sexual do traBALHO; DisCRIMINAÇÃo INTERSECCIONAL; EFICÁCIA DAS NORMAS TRABALHISTAS.

ABSTRACT The simultaneous reorganization of work in the salaried field and in the domes-
tic field in contemporary times directly impacts the discrimination of female productive
work, which acts in an intersectional way. From this juridical-social context, the present
theoretical research turns to the analysis of the current national legal regime for the pro-
tection of female work, through an intersectional perspective, to ascertain the reasons for
the ineffectiveness of such norms in Brazilian daily life and its relationship with the sexual
division of labor. Passing through a context of a culture with patriarchal and sexist origins,
which still permeate society and, consequently, the laws. In this juridical-sociological rese-
arch, theoretical frameworks of Labor Law were adopted in its matrix of general legal the-

* Parte desta pesquisa foi financiada com bolsa de fomento à pesquisa concedida pela Coordenação de Aperfeiçoamento de Pessoal de Nível Superior (CAPES) - Brasil ao autor. 
ory, as well as in its perspective of legal labor sociology, in a three-dimensional conception of the Science of Law. Seeking an articulation between legal discipline and other related branches, such as sociology and philosophy.

KeYwords: Labor LaW; Woman's WOrK; SeXual Division of LabOr; InTERSECTIONAL DiSCRIMINATION; EFFECTIVENESS OF LABOR STANDARDS.

\section{INTRODUÇÃo ${ }^{1}$}

Esse texto é para Tia Ciata ${ }^{2}$, Carolina Maria de Jesus ${ }^{3}$, Enedita Marques ${ }^{4}$, Laudelina de Campos $^{5}$ e Antonieta de Barros ${ }^{6}$ e tantas outras que ousaram desafiar todo esse constructo jurídico-histórico-social-masculino que demonstra um pacto com a branquitude (RIBEIRO, 2019) e subverteram aquele lugar subalterno que lhes foi imposto.

A reorganização simultânea do trabalho no campo assalariado e no campo doméstico na contemporaneidade impacta diretamente na discriminação do trabalho produtivo feminino, que atua de forma interseccional. A partir desse contexto jurídico-social, a presente pesquisa teórica volta-se para a análise do atual regime jurídico pátri(arcal)o de proteção do trabalho feminino, mediante um método interseccional, para averiguar as razões da (in)eficácia $^{7}$ de tais normas no cotidiano brasileiro e sua relação com a divisão sexual do trabalho.

A vertente metodológica adotada é a jurídico-sociológica (GUSTIN; DIAS, 2015, p. 22), visto que se compreende a relação dos fenômenos sociológicos e jurídicos, uma vez que este trabalho não se preocupa apenas com a eficiência das relações normativas, mas com sua (in)eficácia e (in)efetividade.

\section{Sociologia do trabalho e (FALta de) PRoteção JURídica do traba- LHO FEMININO}

A discriminação de gênero nas relações laborais brasileiras remete a uma problemática proveniente do constructo social capitalista-burguesa-hetero-colonial que se mulher como uma trabalhadora naturalmente inferior ao homem e que deve estar restrita ao espaço no lar.

A qualificação da mulher em comparação ao homem não é considerada no mercado de trabalho e sua tripla jornada de labor - doméstico, de cuidado e produtivo - é inviabilizada. Ressalta-se a existência de uma desigualdade no mercado de trabalho que perpassa

A construção desse texto não seria possível sem a orientação da pesquisadora e professora Dra. Flávia Souza Máximo Pereira que é uma referência para todo o trabalho.

2 Mãe de Santo e quituteira que viveu de 1854-1924 foi uma das organizadoras de festas, fomentou o ritmo musical e as religiões de matriz africana no Brasil. Foi chamada para ajudar no tratamento de uma ferida do presidente Venceslau Brás (NEXO, 2019).

3 Escritora negra que viveu de 1914-1977 e escreveu sob a marginalização em um contexto de urbanização e industrialização. Suas obras foram traduzidas para 29 países e vendidas em mais de 40 países (NEXO, 2019).

4 Foi a primeira engenheira negra do Brasil, tendo se graduado no curso de engenharia civil. Ocupou cargos de destaque no setor público e teve seu reconhecimento ainda em vida (NEXO, 2019).

5 Foi pioneira na luta das domésticas, lugar ainda marginalizado no Brasil, e contribuiu na luta contra a opressão de raça, gênero e classe (NEXO, 2019).

6 Desafiou lugares e foi a primeira parlamentar negra da história do Brasil (NEXO, 2019).

7 Essa presente dicotomia do "(in)eficácia" se tem a construção que o arcabouço jurídico é construído em um sistema de exploração patriarcal. 
por séculos, mas pouco se quer discutir sobre costumes e mentalidades enraizadas em uma cultura patriarcal e machista. ${ }^{8}$

Dentro disso, verifica-se que o trabalho doméstico e de cuidado gratuito é excluído da categoria jurídica "trabalho", ou seja, não gera nenhuma repercussão na esfera juslaboral (HIRATA; KERGOAT, 2007), o que reafirma no direito uma vocação moderna/colonial que coloca o sujeito padrão masculino em uma posição de superioridade, tendo em vista que o trabalho reprodutivo é naturalmente atribuído às mulheres.

Como trabalho reprodutivo entende-se, por um lado, o trabalho doméstico, como atividade realizada por terceiros em ambiente familiar, em geral sem finalidades lucrativas e mediante remuneração, que possui padrões de proteção jurídica reduzidos, quando não inexistentes (DUARTE; PEREIRA; NICOLI, 2017). De outro, o trabalho familiar não remunerado, que também se desenvolve em ambiente doméstico, que consiste no cuidado gratuito da própria família, o que, nas clássicas leituras do Direito, daria à atividade uma intenção graciosa, imbricada pelo afeto, excluindo a possibilidade de restar configurada uma relação de trabalho, sendo a proteção social, quando existente, limitada a certas prestações previdenciárias $^{9}$ (DUARTE; PEREIRA; NICOLI, 2017, p. 7). Nas palavras de Barbara Duarte, Flávia Souza Máximo Pereira e Pedro Nicoli (2017, p. 8):

As proximidades entre essas duas realidades se revelam pelo fato de ambas, por caminhos distintos, incorporarem as bases dos lugares socialmente normativos do dever feminino de cuidado e da divisão sexual do trabalho. Essas duas formas de atividades domésticas de cuidado estão associadas àquilo que a literatura feminista chama trabalho reprodutivo, em funções como o cuidado da família, da prole e do lar. Profissionalmente, como faxineiras, zeladoras, cozinheiras, babás, cuidadoras de idosos. Na família, como esposas, donas de casa, mães. Por mais que tenham avançado no trabalho, direito, educação e sexualidade, as mulheres parecem continuar "condenadas à pena de "trabalhos domésticos perpétuos" vivendo sob expropriações políticas de elementos da composição biológica. (DUARTE; PEREIRA; NICOLI, 2017, p. 8).

Nesse sentido, faz-se necessário proteger trabalho feminino não por ser somente uma simples soma do trabalho doméstico ao trabalho profissional propriamente dito, mas também pela sua exclusão ser intolerante à figura feminina, deixando, portanto, brechas para perpetuar a discriminação de gênero. Dessa forma, é preciso entender a origem desse sistema discriminatório e buscar sua reestruturação.

Segundo Hirata e Kergoat (2007, p. 596), a discriminação de gênero nas relações laborais decorre de uma histórica divisão sexual do trabalho que demonstra que as desigualdades de gênero no tocante ao labor são sistemáticas. Tais desigualdades são estruturadas sobre processos pelos quais a sociedade utiliza-se de uma diferenciação para hierarquizar

8 Segundo o último Relatório da desigualdade de Gênero elaborado pelo Fórum Mundial Internacional o Brasil demorará 57 anos para acabar com a desigualdade de gênero entre mulheres e homens (FMI, 2019).

9 Aquele que exerce atividade laboral não remunerada de caráter familiar pode, por ato voluntário, filiar-se como segurado facultativo da Previdência Social, nos termos do art. 11, parágrafo $1^{\circ}$, I do Decreto $\mathrm{n}$. 3.048/99, tendo acesso aos benefícios previdenciários consubstanciados em aposentadoria por idade, aposentadoria por tempo de contribuição, por invalidez, salário-maternidade, auxílio-doença, pensão por morte e auxílio-reclusão para os dependentes, assim como acesso aos serviços previdenciários. 
as atividades laborais, valorizando mais o trabalho masculino do que aquele feminino, e, consequentemente, hierarquizando os sexos para criar um sistema de gênero no trabalho (HIRATA; KERGOAT, 2007, p. 597).

Essa superior valorização do trabalho masculino em detrimento do feminino e a atribuição do trabalho reprodutivo à mulher é inerente ao cotidiano, permanecendo de uma forma naturalizada, passando-se de geração para geração a noção de que o "instinto materno" deve prevalecer sobre os interesses profissionais de cada mulher. Dessa maneira, as mulheres creem que, em razão dos cuidados com os filhos e do lar, sua vida profissional deve ser ignorada em prol do bem estar da família.

Entretanto, em um processo histórico de conscientização e resistência, fruto dos movimentos feministas, que lutavam para que o trabalho reprodutivo não fosse exercido exclusivamente pela mulher, a opressão de gênero começou a ser reconhecida pelo ramo juslaboral, em razão de estudos da sociologia do trabalho, que começaram a rediscutir a divisão sexual do trabalho. Hirata e Kergoat (2007, p. 598) explicam que essa nova maneira de pensar o trabalho teve muitas consequências:

Por uma espécie de efeito boomerang, depois que "a família", na forma de entidade natural, biológica, se esfacelou para ressurgir prioritariamente como lugar de exercício de um trabalho, foi a vez de implodir a esfera do trabalho assalariado, pensado até então apenas em torno do trabalho produtivo e da figura do trabalhador masculino, qualificado, branco. (HIRATA; KERGOAT, 2007, p. 598).

Assim, a sociologia do trabalho propôs uma releitura dos conceitos e qualificações que abarcam a categoria "trabalho", tentando romper com o paradigma de homem-provedor/mulher-cuidadora, o que gerou repercussões jurídicas.

Abriu-se espaço para uma interpretação, na qual a mulher começou a ser notada pela sua capacidade e competência, inserindo-se no trabalho produtivo nos mais diversos ramos, a exemplo da política e das carreiras militares, que por muitas décadas foram dominadas exclusivamente por homens, e que agora começam aos poucos a serem ocupados por rostos femininos, ainda que em condições desiguais.

Para entender melhor a discriminação de gênero nas relações laborais e suas repercussões jurídicas, é necessário abordar o conceito de divisão sexual do trabalho.

\subsection{Divisão sexual do trabalho e discriminação de gênero}

Compreender melhor as relações sociais e seu entrelaçamento, analisá-las e elaborar um método para pensá-las é dar um passo em direção à sua superação da desigualdade de gênero no mercado de trabalho (KERGOAT, 2010, p. 99). Nesse sentido, para investigar a falta de eficácia das normas do trabalho feminino, em termos de redução de desigualdade no mercado de trabalho, é indispensável analisar como se dá a apropriação do trabalho de um grupo por outro, formadas pela divisão do trabalho entre os sexos e da distribuição do trabalho reprodutivo entre mulheres.

Hirata e Kergoat (2007, p. 596) conceituam este termo da sociologia laboral que se reflete diretamente nas normas de proteção do trabalho da mulher: 
Trata-se, de um lado, de uma acepção sociográfica: estuda-se a distribuição diferencial de homens e mulheres no mercado de trabalho, nos ofícios e nas profissões, e as variações no tempo e no espaço dessa distribuição; e se analisa como ela se associa à divisão desigual do trabalho doméstico entre os sexos. (HIRATA; KERGOAT, 2007, p. 596).

A divisão sexual do trabalho é a forma de divisão do trabalho decorrente das relações sociais entre os sexos que tem como características a designação prioritária dos homens à esfera produtiva e das mulheres à esfera reprodutiva e, simultaneamente, a apropriação pelos homens das funções profissionais com maior valor social adicionado (HIRATA; KERGOAT, 2007, p. 598). Hirata e Kergoat (2007, p. 600) continuam ao elencar dois princípios que norteiam a divisão social do trabalho:

Essa forma particular da divisão social do trabalho tem dois princípios organizadores: o princípio de separação (existem trabalhos de homens e trabalhos de mulheres) e o princípio hierárquico (um trabalho de homem "vale" mais que um trabalho de mulher). Esses princípios são válidos para todas as sociedades conhecidas, no tempo e no espaço. Podem ser aplicados mediante um processo específico de legitimação, a ideologia naturalista. Esta rebaixa o gênero ao sexo biológico, reduz as práticas sociais a "papéis sociais" sexuados que remetem ao destino natural da espécie. (HIRATA; KERGOAT, 2007, p. 600).

Assim, em razão da divisão sexual do trabalho, a mulher sempre fica sobrecarregada por uma tripla jornada de tarefa doméstica, de cuidado e de trabalho produtivo, o que necessariamente faz com ela seja prejudicada quando entra no mercado de trabalho, seja por desigualdade em termos de remuneração, seja em razão de ocupações subalternas. Portanto, tendo em vista o tempo de disponibilidade reduzido para o trabalho produtivo, a mulher é destinada a posições instáveis no mercado de trabalho, em empregos mais precários, a exemplo do trabalho intermitente, do trabalho a tempo parcial e do trabalho terceirizado.

Esse fenômeno é denominado pela doutrina de temporalidades sexuadas do trabalho (HIRATA; KERGOAT, 2007, p. 598) que demonstra que trabalhos precários, ou seja, aqueles que não envolvem contrato de emprego a tempo indeterminado, são típicos femininos, via de consequência da não disponibilidade de tempo integral para estar no trabalho produtivo. Em razão dessa divisão sexual do trabalho, torna-se evidente porque as mulheres estão ainda em condição de subalternidade no mercado de trabalho.

Tal desigualdade na esfera produtiva é ainda mais profunda quando analisamos a inserção laboral da mulher sob a perspectiva de raça e classe, conjugada com a opressão de gênero, em uma ótica interseccional. Essas desigualdades de gênero, raça e classe são os eixos que estruturam o quadro de desigualdade nas relações de trabalho no Brasil, tendo em vista que repercutem na permanência e propagação da exclusão social.

Como a presente pesquisa busca propostas para reverter a cultura de hierarquização masculina sobre a feminina no mercado de trabalho brasileiro, atribuindo eficácia às normas trabalhistas em face da discriminação de gênero, apresenta-se uma abordagem do conceito de interseccionalidade. 


\subsection{Conceito de interseccionalidade}

O conceito de divisão sexual do trabalho está imbricado com a construção das interseccionalidades, visto que, quando uma mulher vai para a esfera produtiva, não há uma inversão de papéis no qual o marido assume as tarefas domésticas e de cuidado. O que se vê na prática é outra mulher assumindo esse posto, via de regra, uma mulher negra e pobre (que vai ocupar os cargos de empregada doméstica e diarista, além dos cargos do setor de cuidado).

O quadro da interseccionalidade não é perceptível apenas no trabalho reprodutivo, tendo em vista que ao destrincharmos a "categoria mulher" nos trabalhos mais precários, por exemplo, funções de telemarketing e outros cargos tipicamente terceirizados, nota-se que a maioria das trabalhadoras são mulheres negras e pobres, uma vez que são os piores tipos de trabalho. Além dessas subalternidades sociais geradas por raça e classe no trabalho da mulher, é nítida a atuação da opressão relacionada à identidade de gênero nesse setor, geralmente ocupado por mulheres trans, em razão da invisibilidade que é inerente a esse tipo de labor.

$\mathrm{O}$ conceito de interseccionalidade foi introduzido na academia a partir do Feminismo Negro, desde o início dos anos de 1990, dentro de um quadro interdisciplinar, pela jurista Kimberlé Crenshaw e outras pesquisadoras inglesas, norte-americanas, canadenses e alemãs (HIRATA; KERGOAT, 2007, p. 598). Crenshaw focaliza sobretudo as intersecções da raça e do gênero nas relações jurídicas, abordando parcial ou perifericamente classe ou sexualidade (HIRATA, 2014, p. 62). Nas palavras de Crenshaw (2002, p. 177):

\footnotetext{
A associação de sistemas múltiplos de subordinação tem sido descrita de vários modos: discriminação composta, cargas múltiplas, ou como dupla ou tripla discriminação. A interseccionalidade é uma conceituação do problema que busca capturar as consequências estruturais e dinâmicas da interação entre dois ou mais eixos da subordinação. Ela trata especificamente da forma pela qual o racismo, o patriarcalismo, a opressão de classe e outros sistemas discriminatórios criam desigualdades básicas que estruturam as posições relativas de mulheres, raças, etnias, classes e outras. Além disso, a interseccionalidade trata da forma como ações e políticas específicas geram opressões que fluem ao longo de tais eixos, constituindo aspectos dinâmicos ou ativos do desempoderamento. (CRENSHAW, 2002, p. 177).
}

A reorganização simultânea do trabalho no campo assalariado e no campo reprodutivo impacta diretamente na discriminação do trabalho feminino, a qual atua de forma interseccional. Principalmente, em relação à externalização do trabalho doméstico, na perspectiva das faxineiras, empregadas domésticas, babás e cuidadoras, há uma delegação do trabalho doméstico e familiar a outras mulheres que se encontram em situação subalterna em termos interseccionais de classe e gênero (KERGOAT, 2010, p. 94). Kergoat (2010, p. 95) explica essa relação:

A participação da mulher no mercado de trabalho aumenta, mas as segmentações, horizontais e verticais, entre empregos masculinos e femininos, perduram. As desigualdades de salário persistem, e as mulheres continuam a assumir o trabalho doméstico. A meu ver, no entanto, isso não representa nenhuma aporia ou contradição interna às relações sociais de sexo, mas aponta para o fato de que o capitalismo tem necessidade de uma mão de obra flexível, que 
empenhe cada vez mais sua subjetividade: o trabalho doméstico assumido pelas mulheres libera os homens e, para as mulheres de alta renda, há a possibilidade de externalização do trabalho doméstico para outras mulheres. (KERGOAT, 2010, p. 95).

A desigualdade no mercado de trabalho é maior quando se analisa o perfil das trabalhadoras mediante o cruzamento das categorias de gênero, classe e raça. Por isso, Patrícia Hill Collins (2013) considera a interseccionalidade concomitantemente como um projeto de conhecimento e uma arma política de resistência para a mulher periférica negra, pois diz respeito a condições sociais de produção de conhecimento e à justiça social. No mesmo sentido, Danièle Kergoat (2010, p. 94) afirma a necessidade de pensar conjuntamente as dominações, a fim de não contribuir para a reprodução de desigualdades.

Assim, a interseccionalidade de um método que trata da forma como ações e políticas específicas geram opressões que fluem ao longo de tais eixos, constituindo aspectos dinâmicos ou ativos do (des)empoderamento. Sob essa perspectiva, o social estrutura-se em torno de tensões que produzem grupos (as classes sociais, mas também as classes de sexo e as classes de raça). Adota-se a concepção da socióloga francesa Danièle Kergoat (2016, p. 22) de que esses grupos sociais se constituem e se relacionam em torno de uma questão: formas da divisão do trabalho (KERGOAT, 2016, p. 22). Desse modo, o suposto paradoxo aponta para a imbricação, na própria gênese da divisão sexual do trabalho produtivo e reprodutivo, de diferentes relações sociais, e que, portanto, não podem ser abordadas da mesma maneira (KERGOAT, 2010, p. 94).

A partir desse contexto jurídico-social, o trabalho volta-se para a análise do atual regime jurídico pátrio de proteção do trabalho feminino, mediante uma ótica interseccional, para averiguar a eficácia de tais normas no cotidiano brasileiro e sua relação com a divisão sexual do trabalho.

\section{PRINCIPAIS NORMAS LABORAIS CONTEMPORÂNEAS DE PROTEÇÃO DO TRA- BALHO FEMININO NO BRASIL}

Em momentos da história, no mundo e no Brasil, houve a inserção precária das mulheres no mercado de trabalho. Apesar do viés protecionista ser a justificativa alegada para a elaboração de tais normas, muitos desses "protestos a favor" de mulheres foram realizados por homens, preocupados com o desemprego (LOPES, 2006, p. 412).

Pode-se citar, como exemplo, o período da Segunda Guerra Mundial, no qual os homens com idade produtiva estavam lutando, abrindo espaço para as mulheres no mercado de trabalho. No entanto, quando eles retornavam, queriam reassumir sua hegemonia na esfera produtiva. A ação decidida por alguns estadistas provocou medidas de proteção à mulher, mas a causa real dessa proteção foi a necessidade de impedir que, explorando sem limites o braço da mulher e da criança, as fábricas fossem suprimindo o braço masculino, provocando a existência de milhares de desempregados que se tornavam um perigo social (LOPES, 2006, p. 412).

Nesse mesmo contexto do pós-segunda guerra mundial, surge o ideal de Direitos Humanos, mediante à Declaração Universal dos Direitos Humanos pela Organização das 
Nações Unidas (ONU), em 1948, caracterizada por universalidade, indivisibilidade e interdependência desses direitos (COMPARATO, 2010, p. 80).

Os Direitos Humanos foram fruto de uma construção histórica e social de lutas e resistências. Contudo, as situações de violência de direitos das mulheres foram por muito tempo tratadas na história como marginais e não recebiam atenção desse sistema pretensamente universal que, na verdade, foi sempre pautado na experiência hegemônica masculina (SILVA, 2017, p. 168). Crenshaw esclarece a problemática da universalidade dos direitos humanos focada no sujeito masculino (2002, p. 72):

Consequentemente, apesar da garantia formal, a proteção dos direitos humanos
das mulheres foi comprometida à medida que suas experiências poderiam ser
definidas como diferentes das dos homens. Assim, quando mulheres eram deti-
das, torturadas ou lhes eram negados outros direitos civis e políticos, de forma
semelhante como acontecia com os homens, tais abusos eram obviamente per-
cebidos como violações dos direitos humanos. Porém, quando mulheres, sob
custódia, eram estupradas, espancadas no âmbito doméstico ou quando alguma
tradição lhes negava acesso à tomada de decisões, suas diferenças em relação
aos homens tornavam tais abusos. periféricos. em se tratando das garantias bá-
sicas dos direitos humanos. (CRENSHAW, 2002, p. 72).

$\mathrm{Na}$ tentativa de romper com a hegemonia masculina na perspectiva do sujeito universal de direitos humanos, um importante marco foi o ano de 1975, caracterizado por muitas lutas significativas para o movimento feminista que buscava transformações de paradigmas para concretizar a igualdade entre os gêneros. O México foi palco da Primeira Conferência Mundial da Mulher, sob o lema "Igualdade, Desenvolvimento e Paz", cujo tema principal foi a eliminação da discriminação da mulher e o seu avanço social. O ano de 1975 foi declarado pela Assembleia Geral da ONU como o Ano Internacional da Mulher.

Diante dessa necessidade de conferir protagonismo à sujeita feminina no sistema das Nações Unidas, foi editada a Convenção sobre a Eliminação de Todas as Formas de Discriminação contra a Mulher em 1979, que o Brasil ratificou com reservas ${ }^{10}$ em 1984. A plena ratificação da Convenção no país veio somente em 1994, com o Decreto no 26 de 22 de junho (SILVA, 2017, p. 168).

Em 1980, ocorreu a Segunda Conferência Mundial da Mulher sob o lema "Educação, Emprego e Saúde", em Copenhague, para efetivar as metas estabelecidas previamente, além de elencar novos objetivos para acompanhar as demandas da sociedade. Em uma busca de união do Estado, do homem e da mulher, para que fortalecesse ainda mais o movimento, viu-se a necessidade de uma maior participação dos homens nesse processo de busca de igualdade; maior apoio do Estado, com políticas públicas mais efetivas; e uma maior participação das mulheres em posições de poder.

Nessa perspectiva, a Segunda Conferência foi em busca de um aparato jurídico para dar espaço para as mulheres participarem das tomadas de decisões, no âmbito político

10 As reservas efetuadas pelo Brasil foram relativas aos seus artigos 15 , parágrafo $4^{\circ}$, e 16 , parágrafo $1^{\circ}$, alíneas (a), (c), (g) e (h) focam principalmente na possibilidade da mulher ter os mesmos direitos e responsabilidades que o homem durante o casamento, assim, como em matéria de aquisição de propriedade (SILVA, 2017, p. 168). 
e social, destacando como compromissos primordiais a igualdade no acesso à educação, oportunidades no trabalho e atenção à saúde das mulheres.

Com a continuidade da falta de aplicabilidade das metas estabelecidas houve, em 1985, a Terceira Conferência Mundial sobre a Mulher, com tema central de "Estratégias Orientadas ao Futuro, para o Desenvolvimento da Mulher até o Ano 2000", em Nairóbi, buscando garantir a propriedade e controle de propriedade das mulheres, bem como melhorias nos direitos das mulheres em relação à herança, guarda dos filhos e nacionalidade.

A necessidade de criação de tratados internacionais relativos às violações de direitos específicos das mulheres, passando a considerá-las como plenos sujeitos de direitos, foi reconhecida e consagrada pela Conferência Mundial dos Direitos Humanos, de 1993 (COMPARATO, 2010, p. 83).

Consequentemente, em 1995, aconteceu a Quarta Conferência Mundial sobre a Mulher com tema central "Ação para a Igualdade, o Desenvolvimento e a Paz" na China. Para a ONU:

\footnotetext{
[...] a transformação fundamental em Pequim foi o reconhecimento da necessidade de mudar o foco da mulher para o conceito de gênero, reconhecendo que toda a estrutura da sociedade, e todas as relações entre homens e mulheres dentro dela, tiveram que ser reavaliados. Só por essa fundamental reestruturação da sociedade e suas instituições poderiam as mulheres ter plenos poderes para tomar o seu lugar de direito como parceiros iguais aos dos homens em todos os aspectos da vida. Essa mudança representou uma reafirmação de que os direitos das mulheres são direitos humanos e que a igualdade de gênero era uma questão de interesse universal, beneficiando a todos. (ORGANIZAÇÃO DAS NAÇÕES UNIDAS, 2018).
}

No decorrer de tantas lutas pelo reconhecimento das mulheres na sociedade como detentoras de deveres e direitos, iniciou-se uma visível mudança de paradigmas e uma evolução no que diz respeito às normas nacionais e internacionais, em uma constante construção histórica que impulsionou os fatores de sexo e gênero nos textos normativos. Esse percurso histórico de lutas feministas que repercutiu na esfera jurídica é também verificado no Direito Internacional do Trabalho, mediante a evolução das normas da OIT.

A OIT, em 1919, ano de sua criação, editou as Convenções 3 e 4, relativas ao emprego das mulheres antes e depois do parto e ao trabalho noturno das mulheres, respectivamente.

A Convenção 4 da OIT, assim como a posterior Convenção 41 da OIT de 1934, foram ratificadas e denunciadas pelo Brasil, pois proibiam o trabalho noturno para todas as mulheres, em qualquer idade, nas indústrias públicas e privadas, de modo extremamente restritivo (BARROS, 2008, p. 79). A proibição do trabalho noturno da mulher foi baseada em motivos discriminatórios fundados na divisão sexual do trabalho, na qual a mulher deveria ser a "senhora do lar operário", o que restringia as oportunidades de emprego feminino e de igualdade de remuneração (BARROS, 2008, p. 79).

Sucessivamente, a Convenção 45 da OIT, de 1937, proibiu que as mulheres trabalhassem em locais subterrâneos de minas, independente de idade. $\mathrm{O}$ artigo $3^{\circ}$ dessa convenção apresentava algumas exceções para aquelas mulheres que ocupassem cargos de direção e que não executassem trabalho manual; para as trabalhadoras de serviços sanitários e so- 
ciais; para aquelas admitidas para fazer estágio em mina subterrânea, em virtude de estudos profissionais e, para trabalhadora chamada, ocasionalmente, a descer aos subterrâneos da mina, em exercício da profissão de caráter não manual (BARROS, 2008, p. 79).

Apesar de oficialmente ainda estar vigente no Brasil, a Convenção 45 da OIT é considerada uma excessiva restrição ao labor da mulher, a qual não foi recepcionada pelo sistema de igualdade no trabalho instaurado pela Constituição Federal de 1988 (CF/88) (BARROS, 2008, p. 80). A motivação da Convenção fundada na suposta "fragilidade biológica feminina" para esse tipo de trabalho serve para legitimar a posição de inferioridade da mulher como trabalhadora, demonstrando-se discriminatória de gênero (BARROS, 2008, p. 80).

A mudança de paradigma no âmbito da OIT veio em 1951 com Convenção 100 da OIT, ratificada pelo Brasil em 1957, que versava sobre a remuneração entre homens e mulheres em trabalhos de igual valor, para afirmar a necessidade de uma equiparação salarial, também complementada pela Recomendação 90.

Posteriormente, em 1958, houve a edição da Convenção 111, ratificada pelo Brasil em 1965, consagrando o princípio da não-discriminação no emprego e na profissão. O conceito de discriminação no trabalho foi estabelecido pelo art. $1^{\circ}$ da referida convenção:

\footnotetext{
Qualquer distinção, exclusão ou preferência fundada em raça, cor, sexo, religião, opinião, política, ascendência nacional, origem social ou outra distinção, exclusão ou preferência especificada pelo Estado Membro interessado, qualquer que seja sua origem jurídica ou prática e que tenha por fim anular ou alterar a igualdade de oportunidades ou de tratamento no emprego ou profissão (ORGANIZAÇÃO INTERNACIONAL DO TRABALHO, 1958).
}

Essa definição de discriminação em matéria de ocupação e emprego estabelecida pela Convenção 111 da OIT inspirou a Constituição brasileira de 1988 que foi um marco jurídico no país em termos de igualdade de gênero nas relações sociais e, especificamente, nas relações de trabalho.

\subsection{O marco jurídico igualitário formal da Constituição da República Federativa do Brasil de 1988 (CF/88)}

A busca pela promoção da igualdade de gênero no trabalho no Brasil ampliou-se com a CLT, em 1943, mas teve seu ápice com o advento da CF/88. O artigo $5^{\circ}$, caput e inciso I do referido códex determina que todos são iguais perante a lei, sem distinção de qualquer natureza de obrigações e direitos entre homens e mulheres, assim como o art. $3^{\circ}$, IV, que proíbe a discriminação em relação a sexo.

$\mathrm{O}$ art. 226, parágrafo $5^{\circ}$ versa sobre os direitos e deveres referentes à sociedade conjugal que devem ser exercidos igualmente pelo homem e pela mulher, reafirmando a abolição do patriarcado na teoria. $\mathrm{O}$ art. $7^{\circ}, \mathrm{XXX}$ proíbe a diferença de salários, bem como de exercício de funções e de critério de admissão por motivo de sexo, idade, cor ou estado civil.

$\mathrm{Na}$ aparente tentativa de estabelecer a igualdade de gênero especificamente no âmbito do trabalho, a $\mathrm{CF} / 88$ dispôs que a empregada gestante tem direito à garantia provisória de emprego, prevista no art. 10, inciso II, alínea “b”, do Ato das Disposições Constitucionais Transitórias (ADCT), mesmo na hipótese de admissão mediante contrato por tempo determinado, nos termos da súmula 244 do Tribunal Superior do Trabalho (TST). 
No entanto, algumas doutrinadoras, como Taveira (2017), questionam se o intuito protetivo dessa norma é real ou se trata de uma medida discriminatória afirmando que esta proteção para a mulher grávida deveria ser adotada a qualquer trabalhador, sendo vedada a dispensa sem fundamento jurídico e justo motivo, observando-se aquilo que a CF/88 1988 já prevê em seu art. 7º I (TAVEIRA, 2017).

Além disso, conforme Valdete Souto Severo (2018), a proteção oferecida pelo ADCT, que se limita a cinco meses após o parto, nada garante à trabalhadora, pois, após este curto período, ela pode ser dispensada, e a possibilidade de obter novo posto de trabalho, tendo um filho de seis meses, em uma lógica de mais de doze milhões de desempregados, é extremamente baixa.

Como reflexo do dispositivo que estabelece a garantia provisória para a gestante na CF/88, a Lei 9.029/95 proibiu a exigência de atestados de gravidez e esterilização, para efeitos admissionais ou de permanência da relação jurídica de trabalho. $\mathrm{O}$ art. $2^{\circ}$ lei 9.029/95 prevê crime do empregador no caso de exigência de teste ou qualquer outro procedimento relativo à esterilização ou ao estado de gravidez que configurem o incitamento à esterilização genética e promoção do controle de natalidade (BARROS, 2008, p. 80). O rompimento da relação de trabalho por ato discriminatório faculta a empregada optar entre duas alternativas reparatórias: reintegração ou indenização, nos termos do art. $4^{\circ}$ da referida lei (BARROS, 2008, p. 80).

Apesar da importância da CF/88 para os direitos das mulheres no ambiente de trabalho, é crucial ressaltar que esse é ainda um processo em fase de consolidação (LOPES, 2006, p. 407). A discriminação das mulheres no âmbito trabalhista ainda permanece de forma estrutural, em razão de uma cultura patriarcal e opressora que ainda no século XXI possui resquícios de uma civilização retrógrada.

Segundo Magda de Almeida Neves (2013), dados de 2011 da OIT corroboram a permanência das desigualdades no mercado de trabalho brasileiro, na medida em que ainda existe um forte contingente feminino concentrado no trabalho doméstico, caracterizado por situações de precariedade, baixa proteção social, condições inadequadas de trabalho, baixos salários e informalidade. Esse trabalho reprodutivo ainda é considerado "natural" das mulheres e, visto que a aprendizagem ocorre na família, soma-se a essa naturalização a desvalorização dos processos de aquisição de competências que ocorrem fora das instituições formais (NEVES, 2013).

Nesse sentido, a CF/88 declara para o mercado de trabalho brasileiro uma igualdade meramente formal entre os direitos e garantias dos homens e das mulheres no trabalho. Nessa perspectiva, as mulheres buscam atingir uma igualdade material no labor, a fim de gozar de maneira plena os direitos previstos na legislação pátria, o que não é diferente em relação às normas da CLT.

\subsection{Principais normas do trabalho feminino na CLT: proteção $\mathrm{x}$ discriminação}

A CLT estabeleceu um capítulo exclusivo de proteção às trabalhadoras: o Capítulo II, do Título II, denominado "Da proteção do trabalho da Mulher", no qual modificou e organizou as normas dirigidas especificamente às mulheres, distribuindo em cinco seções, quais 
sejam, duração e condições do trabalho, trabalho noturno, período de descanso, métodos e locais de trabalho e proteção à maternidade.

Primeiramente, deve-se destacar que a CLT apresenta uma proteção às trabalhadoras empregadas, de modo que um amplo número de mulheres, que trabalham de forma precária fora do âmbito da relação de emprego, não são abarcadas por essa normativa.

A ideologia imposta pela cultura patriarcal brasileira sempre destinou à mulher a função de zelar pelo marido e a função de procriação, o que afasta a trabalhadora das funções produtivas. Absorvendo esse teor cultural patriarcal, o artigo 391, caput, da CLT estabelece: "Art. 391 - Não constitui justo motivo para a rescisão do contrato de trabalho da mulher o fato de haver contraído matrimônio ou de encontrar-se em estado de gravidez" (BRASIL, 1943).

Os artigos 392 ao 401 da CLT disciplinam a proteção à maternidade. A licença maternidade de 120 dias, sem prejuízo do salário e do emprego, é estabelecida no caput do art. 392 da CLT.

O acréscimo de 60 dias à licença-maternidade surgiu com a Lei n. 11.770/08, mas, para tanto, é necessário que o empregador, por vontade própria, faça parte do Programa Empresa Cidadã, criado pelo referido diploma legal (art. $1^{\circ}$ ). De acordo com o Ministério do Trabalho, no Brasil há cerca de 40 milhões de trabalhadores com carteira assinada entre homens e mulheres. E, segundo a Receita Federal, há cerca de três milhões desses trabalhadores no Programa Empresa Cidadã, o que demonstra o baixo número de empresas em que há a possibilidade de prorrogação da licença-maternidade.

Por outro lado, representando uma mudança significativa de paradigmas, o artigo 392A foi inserido pela lei $\mathrm{n}^{\mathrm{o}}$. 10.421, de 2002, ampliando o direito à licença-maternidade para as mães adotantes. No mesmo sentido, a lei $n^{\circ}$. 12.010, de 3 de agosto de 2009, unificou o período de licença-maternidade para todas as mães. $\mathrm{O}$ acréscimo de 60 dias previsto para as empresas que integram o Programa Empresa Cidadã também aplica-se à adoção ou obtenção de guarda judicial.

Entretanto, apesar do aparente intuito de proteção jurídica da mulher no ambiente de trabalho com a extensão da licença-maternidade, é brutal a diferença de tempo concedida para cuidados dos filhos entre trabalhadores e trabalhadoras. A licença-paternidade, garantida no art. $7^{\circ}$, XIX da $\mathrm{CF} / 88$ e pelo art. $10^{\circ}$, parágrafo $1^{\circ}$ do ADCT é de apenas cinco dias, podendo ser prorrogada para vinte dias no caso de empresas que são integrantes do Programa Empresa Cidadã, nos termos do art. 38 da lei 13.257/16. Além disso, a lei 13.257/16 exige para a prorrogação da licença-paternidade a participação do trabalhador em programas de paternidade responsável, que não são regulamentados, o que esvazia a eficácia da norma.

Já o art. 394-A da CLT ${ }^{11}$, antes da Reforma Trabalhista (Lei 13.467/17), estabelecia

11 Art. 394-A. Sem prejuízo de sua remuneração, nesta incluído o valor do adicional de insalubridade, a empregada deverá ser afastada de: I - atividades consideradas insalubres em grau máximo, enquanto durar a gestação; II - atividades consideradas insalubres em grau médio ou mínimo, quando apresentar atestado de saúde, emitido por médico de confiança da mulher, que recomende o afastamento durante a gestação; III - atividades consideradas insalubres em qualquer grau, quando apresentar atestado de saúde, emitido por médico de confiança da mulher, que recomende o afastamento durante a lactação.[...]§ $2^{\circ}$ Cabe à empresa pagar o adicional de insalubridade à gestante ou à lactante, efetivando-se a compensação, observado o disposto no art. 248 da Constituição Federal, por ocasião do recolhimento das contribuições incidentes sobre a folha de salários e demais rendimentos pagos ou creditados, a qualquer título, à pessoa física que lhe preste 
que a empregada gestante ou lactante fosse afastada, enquanto durasse a gestação e a lactação, de quaisquer atividades insalubres. A nova redação do artigo 394-A da CLT, após a perda de eficácia da Medida Provisória (MP) 808/17.

Desde então, diversas discussões surgiram sobre as contradições presentes na proteção do trabalho da gestante. Sob uma perspectiva interseccional de gênero, raça e classe, tal problemática envolve uma pluralidade de trabalhadoras. Existem evidências em pesquisas da maior subalternização da mulher periférica negra no mercado de trabalho, o que torna necessário repensar essa narrativa histórica, não só no que tange à divisão sexual do trabalho, mas também à divisão racial do trabalho.

Nesse sentido, sobre o trabalho da gestante, devemos ressaltar que existem mulheres em altos cargos que podem "optar" 12 por trocar de emprego em face do descumprimento do art. 394-A da CLT pelo empregador, mas também há aquelas, na base da cadeia, que renunciariam a seus direitos para serem contratadas, trabalhando contra as normas de proteção da saúde em troca da contraprestação do adicional. E mesmo aquelas em altos cargos podem acabar renunciando a sua proteção, pela via da pejotização, para não perder restritos espaços femininos de poder no trabalho (FINELLI; PEREIRA, 2018).

Para algumas autoras, esse critério parece mais interessante em termos de discriminação de gênero do que a homogênea proibição total do trabalho em condições insalubres, que segrega a mulher gestante e lactante de alguns espaços de poder no trabalho e foca exclusivamente na proteção do feto (FINELLI; PEREIRA, 2018). Porém, na visão da trabalhadora periférica - e geralmente negra, em uma análise interseccional - a monetização da sua saúde, assim como a do feto é evidente, pois a liberdade de escolha é inexistente sob uma ótica materialista no sistema capitalista (FINELLI; PEREIRA, 2018).

Segundo Valdete Souto Severo (2018) essas novas disposições colocam a mulher trabalhadora em situação de extrema fragilidade diante do seu empregador. De tal forma que durante a gestação, além de todas as alterações emocionais, hormonais e mesmo de organização da vida, que as mulheres precisam enfrentar, devem ainda se preocupar, em razão da lógica de completa ausência de proteção contra a dispensa, com a manutenção do emprego (SEVERO, 2018).

Portanto, a trabalhadora, a depender do grau de sua necessidade de sobrevivência, fará qualquer coisa para que seu empregador permaneça satisfeito e não a despeça após o término da garantia que lhe confere o art. 10 dos ADCT (SEVERO, 2018). Do mesmo modo, alguém que está retornando da licença-maternidade e que certamente enfrentará dificulda-

serviço. $\S 3^{\circ}$ Quando não for possível que a gestante ou a lactante afastada nos termos do caput deste artigo exerça suas atividades em local salubre na empresa, a hipótese será considerada como gravidez de risco e ensejará a percepção de salário-maternidade, nos termos da Lei no 8.213, de 24 de julho de 1991, durante todo o período de afastamento. (BRASIL, 1943).

12 Everaldo Gaspar Lopes de Andrade questiona com precisão o paradoxo entre trabalho livre e subordinado consolidado na Revolução Industrial, propiciado pelo contrato de trabalho: "O Direito do Trabalho e seus fundamentos desencadearam realmente uma revolução no campo do Direito Privado ou foi ele próprio indispensável para legitimar os modelos de Estado e de sociedade que surgiram após a queda do Absolutismo monárquico - em que os poderes se encontravam nas mãos do clero e da nobreza -, e permitir a ascensão da burguesia nascente ao poder e dar origem ao Estado Liberal centrado no individualismo contratualista, centrado na supremacia do trabalho vendido, comprado, separado da vida e no racionalismo instrumental a serviço da produção capitalista?" (ANDRADE, 2014, p. 21). 
des para manter o emprego, após o período de garantia contra a despedida, certamente se sentirá pressionada a trabalhar em condições insalubres, para conservar o posto de trabalho (SEVERO, 2018).

Contudo, em termos de divisão sexual do trabalho, fica o questionamento sobre as linhas tênues entre proteção e discriminação de gênero nas normas laborais da trabalhadora gestante. A proteção do trabalho em local insalubre, assim como a vedação de dispensa sem justa causa, deveriam ser adotadas para qualquer trabalhador e trabalhadora (FINELLI; PEREIRA, 2018).

No tocante ao artigo 395 da CLT, verifica-se a influência patriarcal e machista na lei trabalhista e o quanto essa dita "proteção" é mais voltada à moral do que à própria saúde das mulheres destinatárias da lei. O referido artigo concede um repouso remunerado de duas semanas apenas às mulheres que tiverem aborto não criminoso ${ }^{13}$. Ocorrendo o aborto "criminoso", a saúde da mulher não é levada em consideração e ela deverá retornar ao trabalho normalmente.

Por fim, o art. 390 da CLT veda que o empregador contrate mulher em serviço que demande o emprego de força muscular superior a 20 quilos para o trabalho contínuo ou 25 quilos, para o trabalho ocasional, enquanto para o homem esse limite é de 60 e 65 quilos, respectivamente. A norma permanece vigente e é comumente apontada pela doutrina como um caso de diferença justa entre homens e mulheres (LOPES, 2006, p. 419).

No entanto, apesar do aparente intuito protetivo, seria muito mais adequado se tal norma fosse estabelecida em razão do biotipo de cada trabalhador e não em razão do sexo, para a construção de um parâmetro de peso que não ultrapasse o limite desejável para a saúde de cada trabalhador. Quando a CLT delimita uma quantidade de peso para a contratação da mulher, observa-se, mais uma vez, a legitimidade jurídica da inferioridade biológica feminina.

A implementação efetiva da igualdade entre mulheres e homens no ambiente de trabalho tende a remodelar radicalmente as teias sociais de dominação patriarcal. Talvez, justamente por essa razão, há sempre um conservadorismo difundido na mudança legislativa no tocante à proteção do trabalho feminino que faz com que, muitas vezes, o Direito do Trabalho possa colaborar para manter o status quo da relação de desigualdade entres os gêneros.

$\mathrm{O}$ desequilíbrio de poder entre gênero masculino e feminino pode ser o motivo pelo qual a defesa do trabalho das mulheres seja retratada como uma especificidade de uma minoria, mesmo que as mulheres sejam maioria na população em geral e na população profissionalmente ativa no Brasil. Diante dessa manutenção da desigualdade de gênero no trabalho, é necessário verificar os motivos pelos quais as normas trabalhistas no Brasil são ineficazes.

\section{Conclusão}

Pelo exposto, conclui-se que a inserção precária das mulheres no mercado de trabalho e a (in)eficácia das normas juslaborais estão diretamente ligadas com a discriminação inter-

13 Sobre a aplicação do artigo 395 da CLT, o artigo 343, § 1º da Instrução Normativa do INSS n ${ }^{\circ}$ 77/2015, presume que houve parto, e não aborto, após seis meses, mesmo que o bebê nasça morto. Nesse caso, há garantia de emprego e licença maternidade. A licença maternidade da empregada gestante não está condicionada ao nascimento com vida do bebê. Se criança morrer após parto, também há direito de licença maternidade e garantia de emprego. 
seccional pela construção de uma sociedade capitalista-branca-masculina-heterocentrada, na qual as construções são centradas em um papel masculino.

A discriminação quando direcionada às mulheres reflexem uma sociedade marcada por relação de gênero e raça ao ser analisada em uma ótica interseccional, haja vista a necessidade, em termos de igualdade nas relações laborais. Dessa forma, é impossível que tais opressões sejam tratadas como variáveis isoladas nas relações de trabalho, especificamente quando analisamos o trabalho feminino.

Insta salientar que existe uma ineficácia em relação à legislação pátria de forma a reafirmar a exclusão da mulher no ambiente laboral ou mesmo uma eficácia ao que esse sistema do direito de propõe ao excluir as mulheres e manter os privilégios masculinos. A razão para a permanência da discriminação intersecional das mulheres nas relações de trabalho não consiste na ausência de dispositivos legais, mas sim devido a uma mentalidade machista e patriarcal que continua em nossa cultura e permeia em nossas leis.

Deve haver uma conexão entre normas que tenham verdadeira aplicabilidade e a mudança de uma mentalidade machista e patriarcal na sociedade, para que os homens se sintam e construam essa mudança e que atuem para tanto, e que as mulheres lutem pelos seus direitos de forma conjunta, ocupando espaços centrais de poder(es), tornando visíveis as desigualdades sobrepostas de raça, classe e gênero no mercado de trabalho.

\section{REFERÊNCIAS $^{14}$}

ANDRADE, Everaldo Gaspar Lopes. O Direito do Trabalho na Filosofia e na Teoria Social Crítica: os sentidos do trabalho subordinado na cultura e no poder das organizações. São Paulo: LTr, 2014.

ANDRÉ, Bruno Antoniasse. Mulheres No Mercado De Trabalho: Desigualdades Salariais Entre Gêneros Na Atualidade. Caleidoscópio, v. 1, n. 4, p. 119-124, 2014

BARROS, Alice Monteiro de. Cidadania, relações de gênero e relações de trabalho. Rev.

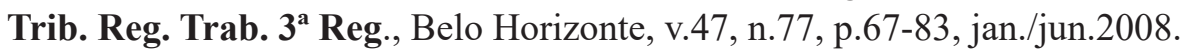

BIROLI, Flávia; MIGUEL, Luis Felipe.Gênero, Raça, Classe: opressões cruzadas e convergênciasnareproduçãodasdesigualdades. Mediaçðes, v. 20, n. 2, p. 27, 2015.

CARVALHO, Sandro Sacchet; SOUZA JÚNIOR, José Ronaldo de Castro. Mercado de Trabalho. Instituto de Pesquisa Econômica e Aplicada, 2016. P 27

CRENSHAW, Kimberlé. Documento para o encontro de especialistas em aspectos da discriminação racial relativos ao gênero. Revista estudos feministas, v. 10, n. 1, 2002.

\footnotetext{
14 Como forma de desobediência epistêmica foram utilizadas majoritariamente mulheres para a construção do trabalho.
} 
COLLINS, PatriciaHill.Pensamento feminista negro: conhecimento, consciência e a política do empoderamento. Seminário “Teoria Feminista”, Cebrap, 2013.

COMPARATO, Fábio Konder. A afirmação histórica dos Direitos Humanos. São Paulo: Saraiva, 2010.

COSTA HIGA, Flávio da. Assédio sexual no trabalho e discriminação de gênero: duas faces da mesma moeda?.Revista Direito GV, v. 12, n. 2, p. 484-515, 2016.

DAVIS, Angela. Mulheres, raça e classe. São Paulo, Boitempo, 2016.

DE ALMEIDA NEVES, Magda. Anotações sobre trabalho e gênero. Cadernos de Pesquisa, v. 43, n. 149, p. 404-421, 2013.

DUARTE, Bárbara Almeida; PEREIRA, Flávia Souza Máximo; NICOLI, Pedro Augusto Gravatá. O valor do trabalho reprodutivo na economia feminista e seu desvalor jurídico: por uma crítica político-econômica do feminismo ao Direito. III Encontro da rede nacional de pesquisas e estudos em direito do trabalho e da seguridade social (RENAPEDTS).Belo Horizonte, 2017.

FINELLI, Lília Carvalho. PEREIRA, Flávia Souza Máximo. Possibilidade de autorização do trabalho da gestante ou da lactante em ambiente insalubre: notas sobre a responsabilidade dos médicos e impactos previdenciários. In: JANOTTI, Cláudio (Org.). Seguridade Social e Meio Ambiente de Trabalho: direitos humanos nas relações sociais. Belo Horizonte: RTM, 2018.

FONTÃO, Maria Angélica Breda. As conferências da ONU e o movimento de mulheres: construção de uma agenda internacional. 2012.

GIBB, Lygia Sabbag Fares et al. A tendência de despadronização da jornada de trabalho: configuração no Brasil e impacto nas mulheres. 2017.

GUSTIN, Miracy Barbosa de Sousa; DIAS, Maria Tereza Fonseca. (Re)Pensando a Pesquisa Jurídica. $5^{\mathrm{a}}$ ed. Belo Horizonte: Del Rey, 2015.

HIRATA, Helena; KERGOAT, Danièle. Novas configurações da divisão sexual do traba1ho. Cadernos de pesquisa, v. 37, n. 132, p. 595-609, 2007.

HIRATA, Helena. Gênero, classe e raça Interseccionalidade e consubstancialidade das relações sociais. Tempo social, v. 26, n. 1, p. 61-73, 2014.

HOOKS, Bell. Intelectuais negras. Estudos feministas, v. 3, n. 2, p. 464, 1995. 
INSTITUTO BRASILEIRO DE GEOGRAFIA E ESTATÍSTICA (IBGE). Síntese de Indicadores Sociais: uma análise das condições de vida da população brasileira. 2014. Disponível em: <http://biblioteca.ibge.gov.br/visualizacao/livros/liv91983.pdf>. Acesso em 13 mai. 2018.

INSTITUTO DE PESQUISA ECONÔMICA APLICADA (IPEA). Retrato das Desigualdades de Gênero e Raça - 1995 a 2015. 2017. Disponível em <http://www.ipea.gov.br/ portal/images/stories/PDFs/170306_retrato_das_desigualdades_de_genero_raca.pdf $>$. Acesso em 13 jun. 2018.

INSTITUTO DE PESQUISA ECONÔMICA APLICADA (IPEA). Mercado de Trabalho. 2016. Disponível em <http:/www.ipea.gov.br/portal/images/stories/PDFs/conjuntura/161219_cc33_mercado_trabalho.pdf >. Acesso em 24 mai. 2018.

KERGOAT, Danièle. Dinâmica e consubstancialidade das relações sociais. Novos Estudos Cebrap, São Paulo, n. 86, 2010.

KERGOAT, Danièle. O cuidado e a imbricação das relações sociais In HIRATA, Helena; ABREU, Alice Rangel de Paiva, LOMBARDI, Maria Rosa (org.). Gênero e Trabalho no Brasil e na França: perspectivas interseccionais. São Paulo, Editora Boitempo, 2016.

LOPES, Cristiane Maria Sbalqueiro. Direito do trabalho da mulher: da proteção à promoção. Cadernos Pagu, v. 26, n. 1, p. 405-430, 2006.

NEVES, Magda Alemeida. Anotações sobre trabalho e gênero. Cad. Pesquisa. vol.43 no.149 São Paulo May/Aug. 2013.

OLIVEIRA, Rayhanna Fernandes de Souza Oliveira. O lugar do feminino negro no mercado de trabalho sob a perspectiva decolonial: para além do salário e da remuneração. Dissertação apresentada no Programa de Pós-graduação em Direito da Universidade Federal de Minas Gerais. 2019.

ORGANIZAÇÕES DAS NAÇÕES UNIDAS (ONU). A ONU e as mulheres, 2018. Disponível em: < https://nacoesunidas.org/acao/mulheres/ > . Acesso em 22 de mai. 2018.

ORGANIZAÇÕES DAS NAÇÕES UNIDAS (ONU). Conferências Mundiais da Mulher, 2018. Disponível em < http://www.onumulheres.org.br/planeta5050-2030/conferencias/ > . Acesso em 18 de mai. 2018.

ORGANIZAÇÃO INTERNACIONAL DE TRABALHO (OIT). Convenções. Disponível em < http://www.ilo.org/brasilia/convencoes/lang--pt/index.htm >. Acesso em 15 de mai. 2018. 
ORGANIZAÇÃO INTERNACIONAL DE TRABALHO (OIT). Recomendações. Disponível em <http://www.ilo.org/brasilia/convencoes/WCMS_242958/lang--pt/index.htm >. Acesso em 16 de mai. 2018.

ORGANIZAÇÃO INTERNACIONAL DO TRABALHO (OIT). Discriminação em matéria de emprego e ocupação,1960. Disponível em: <http://www.ilo.org/brasilia/convencoes/WCMS_235325/lang--pt/index.htm >. Acesso em: 10 jun. 2018.

QUIJANO, Aníbal. Colonialidad do poder, eurocentrismo e América Latina. In LANDER, Eduardo (org.). A colonialidade do saber: eurocentrismo e ciências sociais. Perspectivas latino-americanas. Buenos Aires: CLACSO, 2005.

SAAVEDRA, Luísa; CÉU TAVEIRA, Maria do; SILVA, Ana Daniela. A subrepresentatividade das mulheres em áreas tipicamente masculinas: Factores explicativos e pistas para a intervenção. Revista Brasileira de Orientação Profissional, v. 11, n. 1, 2010.

SEVERO, Valdete Souto. Proteção contra a despedida: uma medida que protege as trabalhadoras brasileiras, 2018. Disponível em: <http://justificando.cartacapital.com. br/2018/04/05/protecao-contra-a-despedida-uma-medida-que-protege-as-trabalhadoras-brasileiras/>. Acesso em: 10 jun. 2019.

SILVA, Isabela Brandão Araújo da. Direitos humanos para quem? A interseccionalidade como instrumento para o uso emancipatório dos Direitos Humanos In SOUTO MAIOR, Jorge Luiz, VIEIRA, Regina Stela Corrêa. Mulheres em Luta: a outra metade da história do Direito do Trabalho. São Paulo, LTr, 2017.

Não tem os dados dos autores e nem as datas de submissão e aceite. 